\title{
Home detox - supporting patients to overcome alcohol addiction
}

\section{Chris Davis}

General practitioner, East Sydney Doctors, Sydney

\section{Keywords}

alcoholism, alcohol withdrawal, detoxification

Aust Prescr 2018;41:180-2 https://doi.org/10.18773/ austprescr.2018.059

\section{SUMMARY}

Helping a patient through home alcohol detoxification has high patient satisfaction rates and is hugely rewarding for the GP.

The majority of dependent drinkers can detox safely and successfully at home and do not require hospital admission.

Daily review by a GP or nurse is important for at least the first four days.

Prescribing acamprosate, naltrexone or disulfiram is advised to maintain abstinence after detox but should only be used with ongoing support.

Ongoing psychosocial support is essential for recovery.

\section{Introduction}

Alcohol is the most dangerous addictive drug in the world and kills 15 Australians every day. The harms related to alcohol dependence are undisputed, yet discussing alcohol consumption with patients still seems to be a difficult conversation. ${ }^{2,3}$ One could argue that, as well as alcohol's cultural acceptability, this is partly due to the lack of options in primary care for treating alcohol dependency.

Patients with alcohol dependency are often referred to over-burdened tertiary services, or are given a potentially dangerous prescription of diazepam without the support required for a safe detox process. ${ }^{4}$ GPs are well placed to offer a structured home alcohol detox service for their patients.

Home detox is the process of safely withdrawing a dependent drinker from alcohol without admission to an inpatient unit. A recent systematic review ${ }^{5}$ of 20 studies found that community detoxification was safe with high completion rates. It proved that detox in the community, as compared to an inpatient unit, had better drinking outcomes, good acceptability and was between 10.6 and 22.7 times cheaper.

It is often difficult for a patient to ask for help due to the cultural stigma around being branded an 'alcoholic'. A non-judgemental approach and the use of motivational interviewing techniques are essential. Once you have built rapport, a thorough assessment can be undertaken.

There is evidence that home detox is ideal for minority communities such as Aboriginal and Torres Strait Islander people. ${ }^{6}$ This may be extrapolated to culturally and linguistically diverse populations.

\section{How to do a home detox}

At the first appointment, it is recommended that you obtain some baseline observations and blood tests. This should include full blood count, urea and electrolytes, liver function, iron studies, glucose, calcium, magnesium and phosphate. Screen patients with the following questionnaires:

- Alcohol Use Disorders Identification Test (https://patient.info/doctor/alcohol-usedisorders-identification-test-audit)

- Severity of Alcohol Dependence Questionnaire (http://php.nhs.uk/wp-content/uploads/ sites/26/2013/11/SADQ.pdf)

- Kessler Psychological Distress Scale (https://www.tac.vic.gov.au/files-to-move/ media/upload/k10 english.pdf).

To save time, the patient can take these questionnaires home and bring them back to their follow-up appointment.

If you are considering a medicated detox, guidelines suggest starting the patient on oral thiamine $200 \mathrm{mg}$ for two weeks before starting the detox.? Intramuscular injections of thiamine are also beneficial, although these are expensive for the patient (approximately \$100). This reduces the risk of Wernicke's encephalopathy. For low-risk continuing drinkers $100 \mathrm{mg}$ thiamine daily is generally enough.

Diazepam can be used in a weaning regimen (Table) over several days to reduce the risk of seizures and withdrawal syndrome and to ease alcohol cravings. ${ }^{8}$ Oxazepam is a safer alternative if the patient has concurrent liver impairment, as it does not require hepatic oxidation. 


\section{Table Possible diazepam regimen for home detox based on severity of alcohol dependence* 8}

\begin{tabular}{lllll} 
& Mild & Moderate & Severe & Complicated \\
\hline Daily standard drinks & $10-14$ & $15-25$ & $30-40$ & $>50$ \\
SADQ score & $<16$ & $16-30$ & $>30$ & $>30$ plus medical problems \\
Setting & Home & Home & Inpatient services & Inpatient services \\
\hline
\end{tabular}

Suggested prescribing regimen - diazepam

$\begin{array}{lll}\text { Day } 1 & \begin{array}{l}\text { Symptomatic - } \\ 5 \mathrm{mg} 4 \text { times a day and } \\ 5 \mathrm{mg} \text { when required }\end{array} & \begin{array}{l}10 \mathrm{mg} 4 \text { times a day and } \\ 10 \mathrm{mg} \text { when required }\end{array} \\ \text { Day } 2 & 5 \mathrm{mg} 3 \text { times a day } & 5 \mathrm{mg} 4 \text { times a day } \\ \text { Day } 3 & 5 \mathrm{mg} \text { twice a day } & 5 \mathrm{mg} 3 \text { times a day } \\ \text { Day } 4 & 5 \mathrm{mg} \text { at night } & 5 \mathrm{mg} \text { twice a day } \\ \text { Day } 5 & 5 \mathrm{mg} \text { at night } & 5 \mathrm{mg} \text { at night } \\ \text { Day } 6 & & 5 \mathrm{mg} \text { at night }\end{array}$

* As prescribed by the author SADQ Severity of Alcohol Dependence Questionnaire

Encourage patients to keep drink diaries either on paper or on an alcohol tracker phone app (such as AlcoDroid Alcohol Tracker). This not only increases their awareness of how much they are drinking, but also their feelings around their intake. Patients should also be encouraged to access resources at this early stage as it may help them to become more mindful, and to decrease their reliance on alcohol as a coping mechanism. Useful resources include online alcohol counselling and resources at www.ontrack.org.au, the Daybreak phone app, and This Naked Mind book and blog by Annie Grace (https://thisnakedmind.com/blog).

\section{What precautions are needed for a safe detox?}

There are several contraindications to home detox. These include:

- not having access to a support person and safe housing for the first few days

- a history of withdrawal seizures or delirium

- problematic drug use

- suicidality

- serious illness.

A signed patient contract is helpful to set clear boundaries (see Box). Important inclusions are consenting to a urine drug screen on day one, a daily breathalyser test, a scheduled GP review, an agreement that they will not drink or drive while taking benzodiazepines, and an intention to comply with an aftercare program.

\section{Box Example of a patient contract for alcohol detoxification}

\section{CONTRACT}

1. I understand that I must not drive while taking diazepam or during alcohol detoxification.

2. I agree to undertake a urine drug screen before undertaking detox.

3. I understand that the practice has a zero tolerance to the consumption of alcohol during detox. Consuming alcohol while receiving treatment would result in discharge from the detox program.

4. I agree to attend daily while undergoing detoxification.

5. I understand that I will be breathalysed daily before being given medication. The reading needs to be 0 , otherwise medication will not be prescribed.

6. I agree to have blood tests at 1 month and 3 months after completion of my detoxification.

7. I accept that I must attend aftercare such as Alcoholics Anonymous, SMART Recovery or be under the care of a psychologist, having completed my detoxification.

8. I understand and accept that the practice has a ZERO tolerance to aggression and harassment. This would result in immediate discharge.

Signed:

Client: Date:

Doctor Date:

Nurse Date: 
During home detox, in addition to breathalyser tests, daily assessment should include the patient's pulse, temperature and blood pressure. The revised Clinical Institute Withdrawal Assessment can also be used. ${ }^{9}$

\section{What non-drug strategies are there to help withdrawal?}

During the detox, it is important to eat small and frequent meals if possible. Protein-rich foods such as fish, dairy products and vegetables are important along with thiamine and a multivitamin. Plenty of fluids including sweet drinks such as tea or decaffeinated coffee should be encouraged to prevent hypoglycaemia, as well as lots of water. Melatonin can be used for sleep disturbance. Give patients the Alcohol and Drug Information Service (ADIS) telephone number (1800 422 599) in case they need support or advice when the surgery is closed.

\section{What are the common pitfalls with home detox?}

Patients are often very keen to start the detox on the same day they visit their doctor. However, planning is essential and those who rush into it, or go 'cold turkey' themselves, are at much higher risk of a withdrawal syndrome and relapse. It is important to build a relationship with your local addiction specialists because having a good pathway into inpatient care is necessary for high-risk patients.

\section{Is home detox suitable for other drugs of dependence?}

This approach is not designed for other drugs. There is no monitoring system, such as the breathalyser, for other drugs and each one requires a different strategy. Benzodiazepine dependence, for example, needs a weaning schedule over many weeks with regular review and psychological support.

\section{What ongoing support is available?}

Following detox, a structured aftercare program is essential for long-term recovery and for patients to achieve their agreed drinking goals. Aftercare can include GP review, alcohol counselling, cognitive behavioural therapy, exercise physiology, dietetics, group support such as Alcoholics Anonymous and SMART Recovery, and phone apps such as a sobriety counter. Health Pathways and ADIS are excellent GP resources. Naltrexone and acamprosate are both available via the Pharmaceutical Benefits Scheme for relapse prevention. Disulfiram, which is not subsidised, is also available but it should be started with a period of supervised administration as it can be dangerous if the patient drinks alcohol. Disulfiram may however be useful for highly motivated individuals.

\section{Conclusion}

Supporting patients through home detox is proven to be safe, successful and cost-effective. The patientcentred, confidential and discreet location of general practice makes it extremely accessible and provides a safe and non-judgemental environment. $\varangle$

Conflict of interest: none declared

\section{REFERENCES}

1. Gao C, Ogeil RP, Lloyd B. Alcohol's burden of disease in Australia. Canberra: FARE and VicHealth in collaboration with Turning Point; 2014. https://www.vichealth.vic.gov.au/ media-and-resources/publications/alcohols-burden-ofdisease-in-australia [cited 2018 Nov 1]

2. Tam CW, Knight A, Liaw ST. Alcohol screening and brief interventions in primary care - evidence and a pragmatic practice-based approach. Aust Fam Physician 2016;45:767-70.

3. Rapley T, May C, Frances Kaner E. Still a difficult business? Negotiating alcohol-related problems in general practice consultations. Soc Sci Med 2006;63:2418-28. https://doi.org/ 10.1016/j.socscimed.2006.05.025

4. Kroll DS, Nieva HR, Barsky AJ, Linder JA. Benzodiazepines are prescribed more frequently to patients already at risk for benzodiazepine-related adverse events in primary care. J Gen Intern Med 2016;31:1027-34. https://doi.org/10.1007/ s11606-016-3740-0

5. Nadkarni A, Endsley P, Bhatia U, Fuhr DC, Noorani A, Naik A, et al. Community detoxification for alcohol dependence: a systematic review. Drug Alcohol Rev 2017:36:389-99. https://doi.org/10.1111/dar.12440
6. Brett J, Lawrence L, Ivers R, Conigrave K. Outpatient alcohol withdrawal management for Aboriginal and Torres Strait Islander peoples. Aust Fam Physician 2014;43:563-6.

7. Lingford-Hughes AR, Welch S, Peters L, Nutt DJ; British Association for Psychopharmacology, Expert Reviewers Group. BAP updated guidelines: evidence-based guidelines for the pharmacological management of substance abuse, harmful use, addiction and comorbidity: recommendations from BAP. J Psychopharmacol 2012;26:899-952. https://doi.org/10.1177/0269881112444324

8. Jesse S, Bråthen G, Ferrara M, Keindl M, Ben-Menachem E, Tanasescu R, et al. Alcohol withdrawal syndrome: mechanisms, manifestations, and management. Acta Neurol Scand 2017;135:4-16. https://doi.org/10.1111/ane.12671

9. Sullivan JT, Sykora K, Schneiderman J, Naranjo CA, Sellers EM. Assessment of alcohol withdrawal: the revised clinical institute withdrawal assessment for alcohol scale (CIWA-Ar). Br J Addict 1989;84:1353-7.

\section{FURTHER READING}

Rodgers C. Brief interventions for alcohol and other drug use. Aust Prescr 2018;41:117-21. https://doi.org/10.18773/ austprescr.2018.031 